\title{
Influence of chain length of organic modifiers in hydrophobization process on epoxy resin properties
}

\author{
G. Morgiante, M. Piłkowski, J. Marczak (ㅁ]
}

Received: 27 July 2021 / Revised: 28 October 2021 / Accepted: 14 November 2021

(C) The Author(s) 2022

\begin{abstract}
Resins have been widely used in a variety of industry fields for more than a century, such as coatings, adhesives, or automotive. Their low cost and workability are extremely useful in creating more and more advanced materials due to their chemical structure (Ghaffari et al. in Surf Interfaces 17:100340, 2019). Common problem today is the wetting tendency of various materials which in the end can result in further damage in the structure because of atmospheric conditions. Nowadays, scientists are trying to find better ways to improve the properties of coatings or composites in cases like hydrophobicity or icephobicity. One of the examp les are fluorinated organic compounds with good linking properties to the substrate (Qin et al. in Mater Today Commun 22:100770, 2020). Because of that, to im prove the properties of a basic epoxy resin, its chain has been modified with hydrophobic compounds with different chain lengths. Influence of modifiers' molecule size on hydrophobic and ice adhesion properties of obtained epoxy resins has been tested. Chemical composition of prepared coatings was analyzed by FTIR. Moreover, their thermal stability was investigated using TG and DSC measurements. Additionally, wettability of the samples was analyzed with a goniometer. Furthermore, their ice adhesion tests were performed on a dedicated apparatus. As a result, presented work provides a critique overview and concept of promising icephobic and hydrophobic coatings in the industry. Moreover, these products have a high chance to be developed further.
\end{abstract}

This paper was presented at the Surfaces, Interfaces and Coatings Technology International Conference that was held virtually from April 7-9, 2021.

G. Morgiante, M. Piłkowski, J. Marczak ( $\square$ )

Łukasiewicz Research Network - PORT Polish Center for

Technology Development, 147 Stabłowicka St., 54-066

Wrocław, Poland

e-mail: jacek.marczak@port.lukasiewicz.gov.pl
Keywords Epoxy resin, Chemical modification, Organic modifiers, Coatings, Surface wettability

\section{Introduction}

Destructive effects of icing can be observed on many industry areas, e.g., aviation, energetics-wind turbines, or electrical tractions. Ice can lower the efficiency of devices or it may contribute to their destruction, even to aircraft crashes. Due to ice accretion's influence on the ability of solar devices or wind turbines to produce electricity, many of them need to use systems of ice removal. The removal of ice can be classified into two categories: active and passive solutions. Active solutions are methods of removing ice after it has been deposited (deicing systems); these include mechanical scraping, thermal treatments, and the use of deicing fluids. Unfortunately, all of them need electricity to work. Moreover, they are characterized by low efficiency and high emission of $\mathrm{CO}_{2}$ or toxic substances to the environment. ${ }^{3}$ Therefore, new energy-saving solutions are sought. Passive solutions include treatments that can be applied to a surface prior to its use that would prevent the ice from adhering (antiicing systems). Active methods are currently widely used, but passive methods are cheaper and more environmentally friendly. ${ }^{3-5}$ There is no known material that can completely prevent ice or snow from accumulating on its surface. Future solutions should be characterized by better mechanical properties, zero electricity consumption, and high efficiency in various weather conditions and should be in the form of durable coatings. One of the possible options may be the use of hydrophobic coatings. Due to excellent adhesion strength, mechanical property, and water and oil resistance of epoxy coating, epoxy resin has become the most popular coating material in the engineering field. ${ }^{6}$ Modified epoxy antiicing coat- 
ings based on low surface free energy have also received attention from researchers. ${ }^{7-11}$ Daniel et al. used fully bio-based cardanol-modified epoxy and furfurylamine to react to prepare bio-based epoxy. By adding amino silicone oil as a low surface energy modifier to prepare an easy-to-deicing epoxy antiicing coating, ice coating strength can be as low as $\sim 40$ $\mathrm{kPa} .{ }^{12}$ Using high bonding strength of epoxy to introduce hydrophobic nanoparticles (such as PTFE and fluorinated $\mathrm{SiO}_{2}$ ) into coating system, preparation of superhydrophobic coatings can also achieve effect of antiicing and deicing. ${ }^{9,13}$ Moreover, Rolére et al. described research on perfluorinated carboxylic acids as modifiers for epoxy resins. ${ }^{14}$ What is more, they modified different resins with perfluorinated carboxylic acids. In their studies, authors focus on tetra-functional epoxy resin and its surface properties after different curing procedures. Results suggest that curing procedure is a major factor on composite properties. ${ }^{14,15} \mathrm{In}$ the literature, we can find publications that describe only wettability of epoxy resins modified by fluorinated acids without ice adhesion analysis of prepared materials. Glaris et al. described hydrophobicity improvement and modification method of epoxy resin using fluorinated acids, ${ }^{16}$ just like Miccio et al., which correlated fluorine content in epoxy resin with obtained water contact angle using different combinations of epoxy resin/hardener and fluorinated acids. ${ }^{17}$ It is well known that fluorinated polymers are characterized by low surface free energy and high water contact angle. ${ }^{18-21}$ Moreover, epoxy resin modification methods using fluorinated compounds also are described. ${ }^{22,23}$ Few articles present a correlation between chemical structure of fluorinated epoxy resins and ice adhesion properties, which is very important in the case of materials with low ice adhesion preparation for antiicing applications. The most important scientific problem needed to be solved is reducing ice adhesion. Thus, the presented work is focused on research for coating with low ice adhesion preparation and characterization. The mentioned coating material is based on chemical modification of commercial epoxy resin to improve its hydrophobic and ice adhesion properties. The influence of the type of fluorinated modifier and its molecule chain length on modified epoxy resin wettability and ice adhesion has been determined. What is more, the influence of surface chemical composition on surface free energy was established. Additionally, FTIR, DSC, and TGA measurements were carried out to assess chemical composition and thermal parameters of obtained materials.

\section{Experimental methods and materials}

\section{Materials}

Epoxy resin was prepared using commercially available Epidian 5 resin and IDA curing agent by $\mathrm{CIECH}$
Sarzyna S.A. The modifiers used in this research were perfluoroheptanoic acid "C7" (98\%, ABCR), heptadecafluorononanoic acid "C9" ( $>95 \%$, TCI Chemicals) and perfluorododecanoic acid "C12" (96\%, ABCR). The samples have been named by abbreviations of used modifiers (Fig. 1).

\section{Epoxy resin coatings preparation}

The epoxy resin coatings were prepared by mixing epoxy (Epidian 5) with each of the modifiers with specific mass ratios (4 wt $\%$ of modifiers). Modifications have been carried out in the water bath at $80^{\circ} \mathrm{C}$ for $2 \mathrm{~h}$. Obtained modified epoxy resins were cooled down at room temperature. After that, the curing agent was added into the modified resin in mass ratio 0.5:1 and mixed. The prepared mixture was then deposited on microscopic glass and left for curing in room conditions for $48 \mathrm{~h}$. The properties of obtained coating samples were then examined. For the reference sample, unmodified epoxy resin has been taken for further research, which was prepared by mixing Epidian 5 with hardener IDA in mass ratio 0.5:1 and named in the article as "reference."

\section{Characterization}

The wettability of the samples was determined on goniometer, and additionally, their icephobicity was tested on specially constructed apparatus for ice adhesion. Modification correctness was studied by FTIR analysis. Moreover, thermal properties of obtained samples were characterized via DSC and TG measurements.

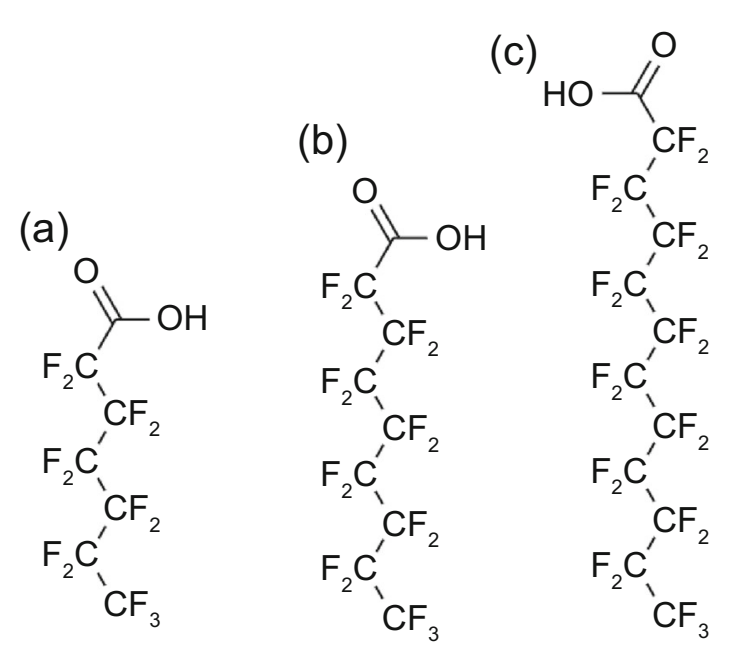

Fig. 1: Structures of used fluoroalkyl modifiers: (a) perfluoroheptanoic acid-“C7," (b) heptadecafluorononanoic acid-“C9," (c) perfluorododecanoic acid-“C12" 


\section{Water contact angle (WCA) measurements and surface free energy (SFE)}

Wettability of obtained coatings has been determined using a goniometer (Data Physics OCA 35) at room temperature and humidity of about $50 \%$. Measurements of the contact angles (CA) have been taken by sessile drop method using $5 \mathrm{~L}$ droplets of distilled water placed on five different points of the sample to ensure that the surface has its homogeneity and to maintain statistically correct results. In addition, surface free energy (SFE) has been calculated by the van Oss-Good method. The calculation has been determined by the standard liquids set: distilled water, diiodomethane (99\%, Sigma-Aldrich CAS: 75-11-6), and glycerin (99.5\%, Sigma-Aldrich CAS: 56-81-5).

\section{Ice adhesion}

The ice adhesion measurements were based on a simple tensile test method. To keep the room temperature stable $\left(19^{\circ} \mathrm{C}\right.$ at $39.7 \%$ humidity), each test was carried out with a closed door of the apparatus (Fig. 2). They were performed using bulk water ice cubes $\left(2 \times 2 \mathrm{~cm}^{2}\right.$, created with $5 \mathrm{~mL}$ of deionized water at $19^{\circ} \mathrm{C}$ in the freezer using silicone molds) which were hung on an actuator, then frozen on the cooled sample surface (with the thickness of $2 \mathrm{~mm}$ ), and left for $10 \mathrm{~min}$. The sample was firstly placed on a cooling system which was maintaining $\sim(-10)^{\circ} \mathrm{C}$ during the whole process. The ice cube (with a density of $830 \mathrm{~kg} /$ $\mathrm{m}^{3}$ ) was pressed to the surface for $30 \mathrm{~s}$ to eliminate the possibility of distance creation between the force probe and the sample. The removal force needed to detach the cube after the settled time was then calculated into the adhesion force by simple equation ${ }^{24}$ :

Ice adhesion strength $=\frac{F_{s}}{A}[\mathrm{kPa}]$

where $F_{s}$ is the removal force needed to detach the ice cube from the surface $[\mathrm{N}]$ and $A$ is the interface area of ice on the sample $\left[\mathrm{mm}^{2}\right]$.

Each of the samples was measured a minimum of three times to receive statistically correct results. Tensometer $(\mathrm{S} 2 \mathrm{M} / 10 \mathrm{~N})$ with the accuracy class 0.02 was used in the apparatus. The loading rate was determined at $0.5 \mathrm{~cm} / \mathrm{s}$. Cohesion strengths of ice cubes were always higher than adhesion strength to the interface area. The cubes did not break and were detached without any signs of crushing.

\section{Fourier-transform infrared (FTIR) spectroscopy}

Structural changes in epoxy resin chains of the prepared samples after the modification process were characterized using Fourier-transform infrared spectroscopy

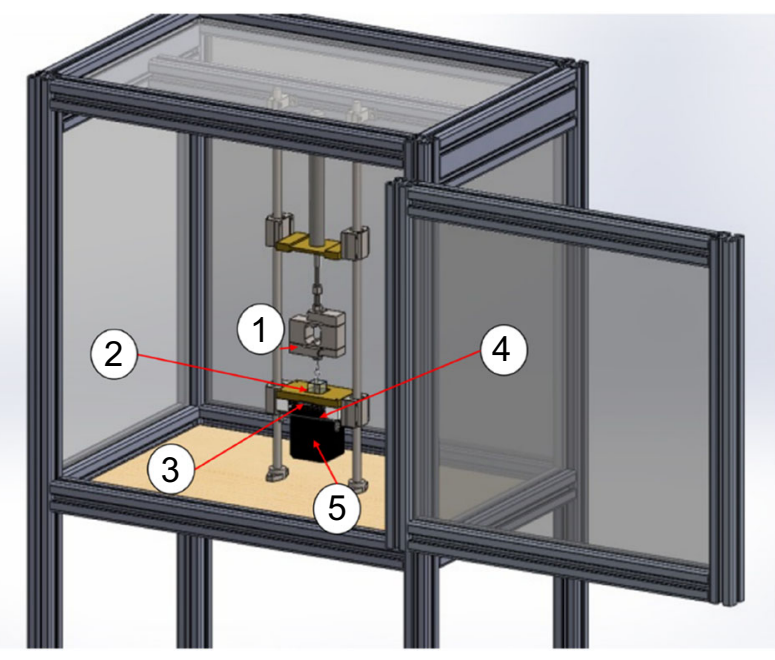

Fig. 2: A scheme of apparatus for ice adhesion measurements and its elements: (1) tensometer; (2) ice cube $(2 \times$ $2 \mathrm{~cm}^{2}$ ); (3) sample; (4) Peltier module; (5) cooling system

(Bruker FTIR Tensor 27). An FTIR apparatus equipped with MIRacle TM ATR attachment was used to obtain an infrared spectrum of absorbed emissions for each of the modifiers. Each of the coatings was scanned in the range of $450-4000 \mathrm{~cm}^{-1}$ at room temperature. The acquired results were used to determine if the modification had occurred correctly.

\section{Thermogravimetry (TG)}

The thermal stability of the cured resins has been measured by thermogravimetric analysis using Mettler Toledo TGA 2. Samples were weighed up to $5 \mathrm{mg}$, placed in corundum crucibles. Measurements were taken under nitrogen atmosphere in the temperature range from 25 to $460^{\circ} \mathrm{C}$. The heating rate was set up at $10 \mathrm{~K} / \mathrm{min}$.

\section{Differential scanning calorimetry (DSC)}

The measurements for the curing reactions were taken using a differential scanning calorimeter (Mettler Toledo DSC1) in DSC analysis. Samples with approximately $3.5 \mathrm{mg}$ mass were put into crucibles and heated. The curves were registered at $10 \mathrm{~K} / \mathrm{min}$ heating rate within the range from 0 to $100^{\circ} \mathrm{C}$ under nitrogen atmosphere.

\section{Results and Discussion}

\section{Water contact angle (WCA) measurements and surface free energy (SFE)}

In this article, epoxy resin (Epidian 5) was modified by fluorinated acids with different chain lengths of their 
molecules. The influence of material modification on its final hydrophobic properties and ice adhesion has been studied. All prepared coating samples were analyzed in case of their hydrophobicity improvement by the chemical modification process. As a reference sample, unmodified epoxy resin has been used. First, water contact angle measurements were taken. The obtained results are shown in Figs. 3 and 4. The highest water contact angle $\left(106 \pm 4^{\circ}\right)$ and simultaneously the lowest surface free energy values $\left(17.9 \pm 5.2 \mathrm{~mJ} / \mathrm{m}^{2}\right)$ were achieved on sample modified by the "C12" compound. It can be also observed that the modification process was successfully ended as the received results were significantly higher in the case of WCA and lower in the case of SFE in all modified samples compared to the reference coating (epoxy resin without modification) although only "C12" showed hydrophobic properties (WCA above $90^{\circ}$ ). It can be observed (Figs. 3 and 4) that with rising chain lengths of modifiers the molecule hydrophobic properties of modified samples are improved. ${ }^{17}$ It is worth emphasizing that the "AB" component in surface free energy has been lowering in values with increasing modifier molecule chain length for modified samples. Moreover, the SFE component "AB" for the modified samples is lower than the "LW" component, indicating greater proportion of long-range interactions between the coating and the liquid. This translated into less possibility of hydrogen bond formation. Weaker interactions between coating and liquid also affect the cleaning properties of the produced coatings, which increased after modification, whereas the "LW" component stayed on a similar level to all modified coatings. The "AB" changes might have occurred due to the reduction in polar groups in the resin as a result of addition of hydrophobic fluorinated chain to the resin backbone chain. The almost linear changes in both WCA and SFE could point into the thesis

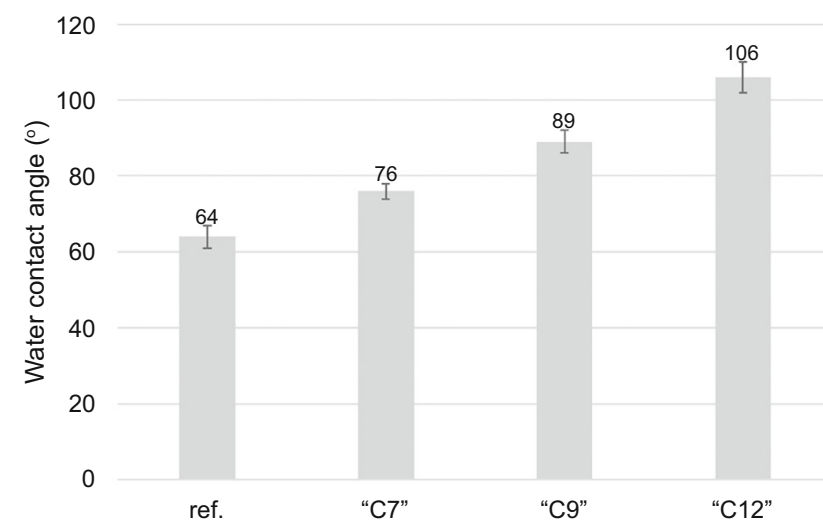

Fig. 3 : WCA values of obtained coatings: ref.-unmodified, cured epoxy resin Epidian 5; epoxy resin Epidian 5 after chemical modification by perfluoroheptanoic acid "C7," heptadecafluorononanoic acid "C9," and perfluorododecanoic acid "C12"

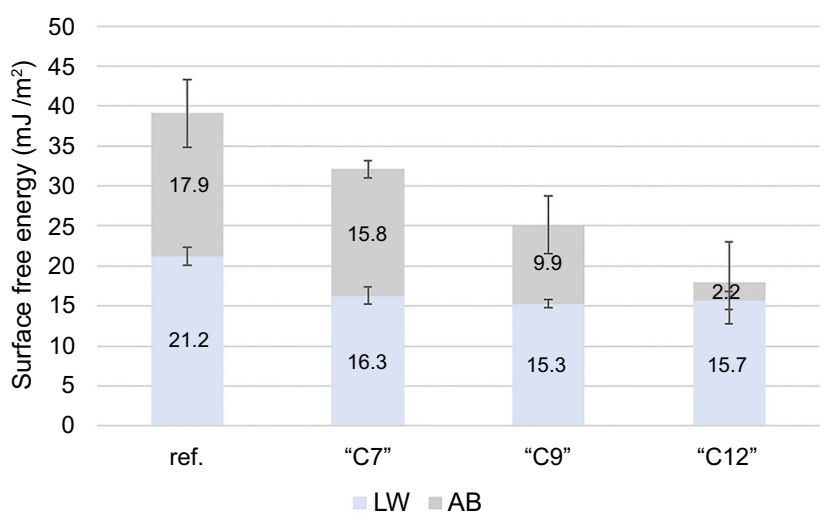

Fig. 4: Calculated surface free energy values with the sections of components of SFE calculation-“AB" (acidbase component) and "LW" (Lifshitz-van der Waals interactions). Obtained values of SFE and its components have been compiled for: ref.-unmodified, cured epoxy resin Epidian 5; epoxy resin Epidian 5 after chemical modification by perfluoroheptanoic acid "C7," heptadecafluorononanoic acid "C9," and perfluorododecanoic acid "C12"

approval as longer fluorinated modifiers' molecule chains enhance hydrophobic properties of modified samples more than the shorter ones.

\section{Ice adhesion}

Improved hydrophobic properties of modified epoxy resin coatings were promising; therefore, ice adhesion tests of the obtained samples were performed for materials with icephobic potential. The results of ice adhesion measurements are presented in Fig. 5.

Hejazi et al. stated that to determine if the material is icephobic, its adhesion to the ice on the surface has to be less than $100 \mathrm{kPa} \cdot{ }^{25}$ From the values in the graph, it can be stated that the reference sample is meeting the requirements to be considered slightly icephobic although its efficiency and properties needed to be improved. Looking further, there can be observed almost a linear decrease in the ice adhesion values of the obtained samples with increasing molecule chain length of used fluorinated compounds for epoxy resin modification. This correlates with the WCA and SFE measurements results obtained for the presented samples (Figs. 3 and 4). Ice adhesion values showed more than $15 \mathrm{kPa}$ difference between modified "C12" and unmodified epoxy resin coating. The modification process improved hydrophobicity and icephobicity of the obtained samples. Moreover, the longer the modifier molecule, the higher the hydrophobicity and icephobicity that can be stated from the values presented in Figs. 3 and 5. Mirshahidi et al. showed that unmodified steel and aluminum substrates are characterized by high ice adhesion values (around $1300 \mathrm{kPa}$ and $1400 \mathrm{kPa}$, respectively). Measurement method is similar to that discussed in this article, but 


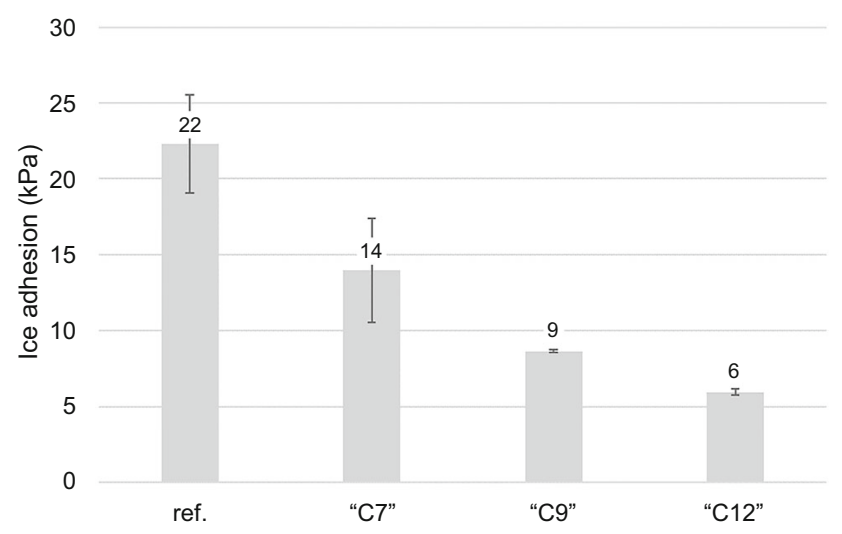

Fig. 5: Ice adhesion results for obtained coatings

tested materials and size and shape of the ice cube are totally different. The obtained results cannot be compared equally, but the differences between unmodified and modified samples can be seen. Unmodified surfaces have significantly higher ice adhesion values than the hydrophobic modified samples. ${ }^{26}$

\section{Fourier-transform infrared (FTIR) spectroscopy}

Correctness of the chemical modification process has been tested using FTIR spectroscopy. Figure 6 shows the FTIR spectra of unmodified and modified coatings of epoxy resin. The colors have been pinned on each of the samples, starting from reference coating (black) through "C7" (red), "C9" (green), and "C12" (blue).

The observed peaks around $3000-2850 \mathrm{~cm}^{-1}$ correspond to $\mathrm{C}-\mathrm{H}$ from $-\mathrm{CH},-\mathrm{CH}_{2}$, and $-\mathrm{CH}_{3}$ groups, which were expected to be strongly present in the spectra considering the structures of used epoxy resin in the research samples. ${ }^{27,28}$ The area of around 1735$1750 \mathrm{~cm}^{-1}$ (peak A) and 1300-1400 $\mathrm{cm}^{-1}$ (peak C) can correspond with $\mathrm{C}=\mathrm{O}$ stretching from ester groups. The peaks listed as a point (B) in the range from 1550 to $1600 \mathrm{~cm}^{-1}$ are characteristic for $\mathrm{C}=\mathrm{C}$ stretching bands for aromatic rings absorption and also for $\mathrm{N}-\mathrm{H}$ bending $\left(1570 \mathrm{~cm}^{-1}\right)$ as the mark of amine groups present in the curing agent, ${ }^{29}$ proving that the crosslinking has been achieved. The peaks range between 1130 and $1160 \mathrm{~cm}^{-1}$ (marked as D) for samples 2,3 , and 4 and have been pinned for $\mathrm{C}-\mathrm{F}$ from $-\mathrm{CF}_{2}$ and $-\mathrm{CF}_{3}$ groups. ${ }^{30}$ It means that the modification has successfully occurred as the reference sample has no peaks in that wavelength. The presented spectra (Fig. 6) for modified resin showed that the modification process occurred correctly which was later on checked with DSC analysis.

\section{Thermogravimetry (TG)}

Data acquired from thermogravimetry analysis allowed for further DSC analysis and helped with the charac-

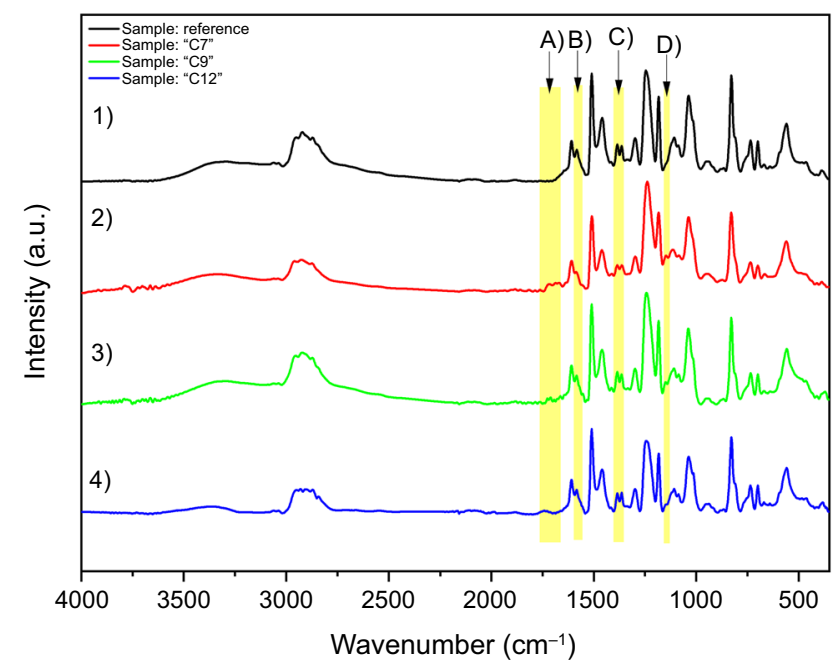

Fig. 6: FTIR spectra of obtained coatings: 1) referenceunmodified, cured epoxy resin Epidian 5; epoxy resin Epidian 5 after chemical modification by: 2) perfluoroheptanoic acid "C7," 3) heptadecafluorononanoic acid "C9," and 4) perfluorododecanoic acid "C12"

terization of thermal resistance of prepared coatings. Measurements were taken on samples of each resin and later on compared with each other to confirm the differences between modified coating and unmodified cured resin and also to check for the threshold for DSC temperature range. The curves have been framed into two-step decomposition ranges to pin the local maximum decomposition temperature and after reaching the plateau-general maximum decomposition temperature. The results collected from the measurements are provided in Fig. 7.

Comparing DTG results of reference sample and modified resins, there can be stated that rising chain length of modifiers could be a factor which has influence on thermal resistance of the material but in not a significant role. It is probably due to the growth of the structural density which could be the reason for decomposition delay for "C7" (red), "C9" (green), and "C12" (blue) with the biggest changes in the first ("C7"). It is apparently seen (Fig. 7) that all samples exhibit similar thermal behavior and two-step decomposition. Even though the $\sim 13-15 \%$ mass temperature has been moved by approximately $30^{\circ} \mathrm{C}$, the maximum decomposition ( $\left.\sim 78-85 \%_{\text {mass }}\right)$ temperature has been registered at the same value $\left(\sim 369^{\circ} \mathrm{C}\right)$ as the other mixes. It would mean that the modifiers used in the modification process can delay the start of the decomposition but cannot be taken as full decomposition retardants as the complete decomposition has been registered at $460^{\circ} \mathrm{C}$ on all samples. 


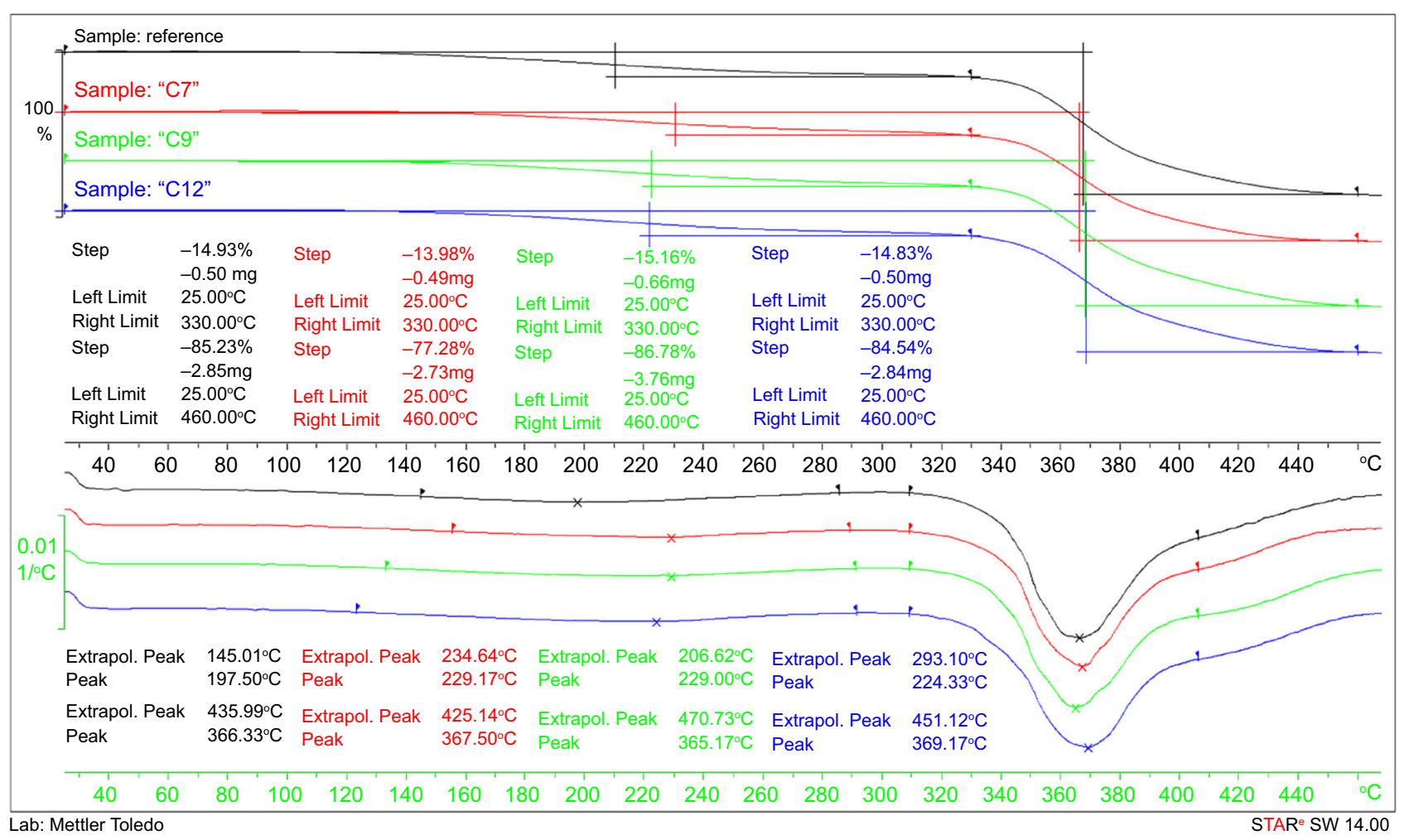

Fig. 7: TGA and DTG graph with the comparison of obtained coatings

\section{Differential scanning calorimetry (DSC)}

DSC measurements were taken to check the curing process of unmodified and modified epoxy resin samples. The graphs were divided into two parts to show the observed changes in $T_{\mathrm{g}}$ and to compare the heating steps shown in Figs. 8 and 9 as the latter were meant to check if the previous heating and cooling were enough for establishing the glass transition temperature $T_{\mathrm{g}}$.

The presented results in Fig. 8 show nonsignificant changes in $T_{\mathrm{g}}$ values. The glass transition temperature for the reference coating was set at $59.63^{\circ} \mathrm{C}$, while for the samples "C7," "C9," and "C12" were set at $57.60^{\circ} \mathrm{C}$; $57.55^{\circ} \mathrm{C}$; and $56.82^{\circ} \mathrm{C}$, respectively. The slight decrease in $T_{\mathrm{g}}$ could be probably an effect of some changes in crosslink density as stated by Miccio et al. that the rising chain length of fluorinated alkyl grafted into the resin seems to be the reason why that phenomenon has occurred. ${ }^{17}$

The repeated heating cycle after cooling (Fig. 9) has been carried out. Due to the fact that the work was provided on multicomponent systems, the second heating shows the results of reorganization of the samples' structure which was achieved by breaching the $T_{\mathrm{g}}$ value at the first cycle (Fig. 8). The glass transition temperature (midpoint ISO) has increased by similar values for all coatings (e.g., from 57.55 to $61.33^{\circ} \mathrm{C}$ for sample "C9"), indicating effective crosslinked polymer structures. ${ }^{31}$

\section{Conclusions}

The effects of modification with fluorinated acids on epoxy resins has been presented in this work. Additionally, focus on the chain length of modifiers and their influence on the hydrophobization process of coatings has been studied. The synthesis between the matrix and fluoroalkyl compounds has been successfully carried out which was proved with FTIR measurements.

The hydrophobicity and icephobicity along with surface free energy have been significantly improved by chemical modification of based epoxy resin (Epidian 5). The higher amount of fluorine groups in the modifier molecule used in the modification process determined the higher hydrophobicity and icephobicity of obtained samples. The prepared coatings have been characterized by slightly changed thermal stability as their starting decomposition temperature has been increased although their full decomposition temperature remained unchanged. The addition of fluorinated molecules into the backbone chain of the resin has its downside as the crosslinking density and glass transition temperature can be violated and decreased with 


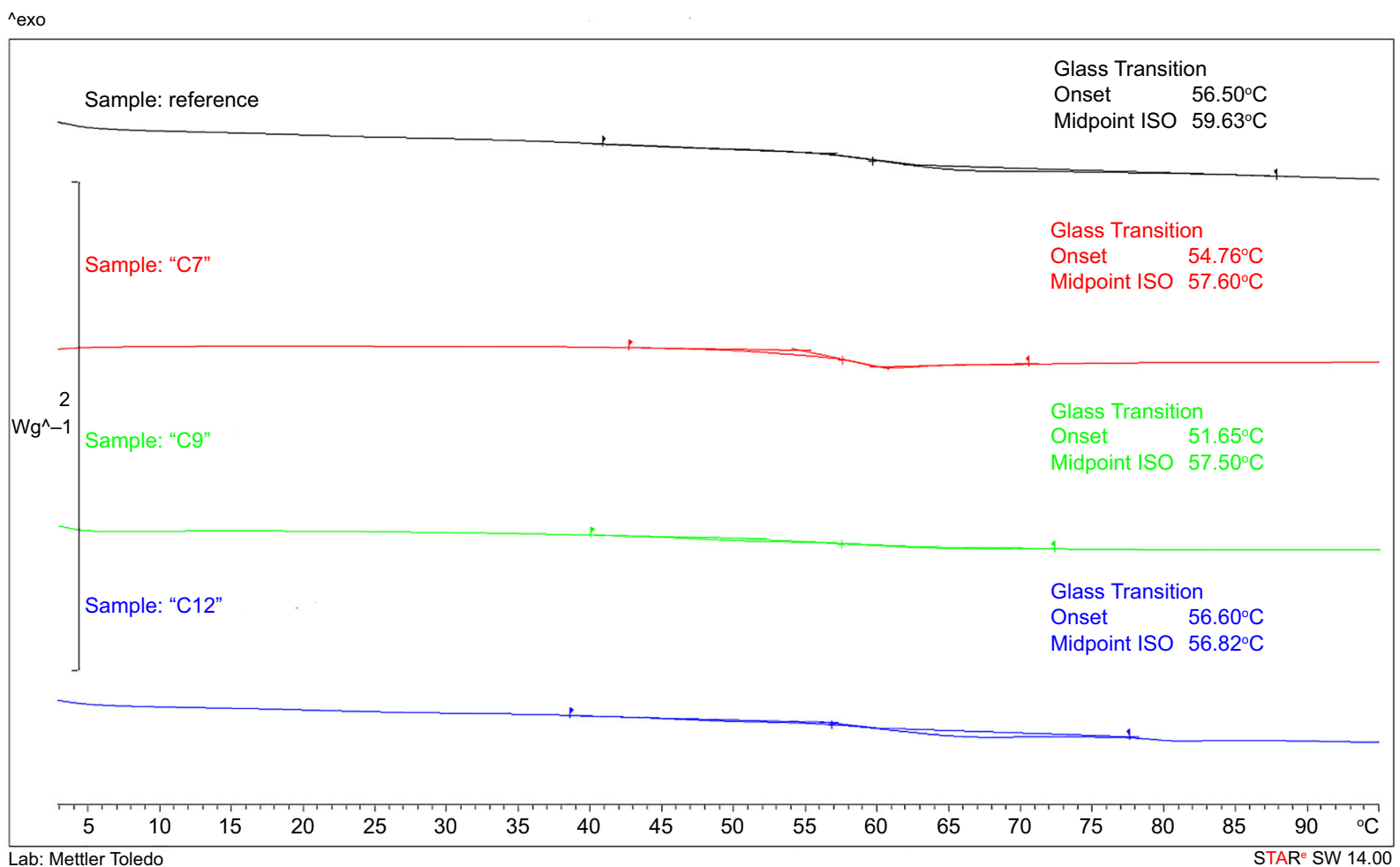

Fig. 8: DSC results of obtained epoxy coatings-first heating cycle

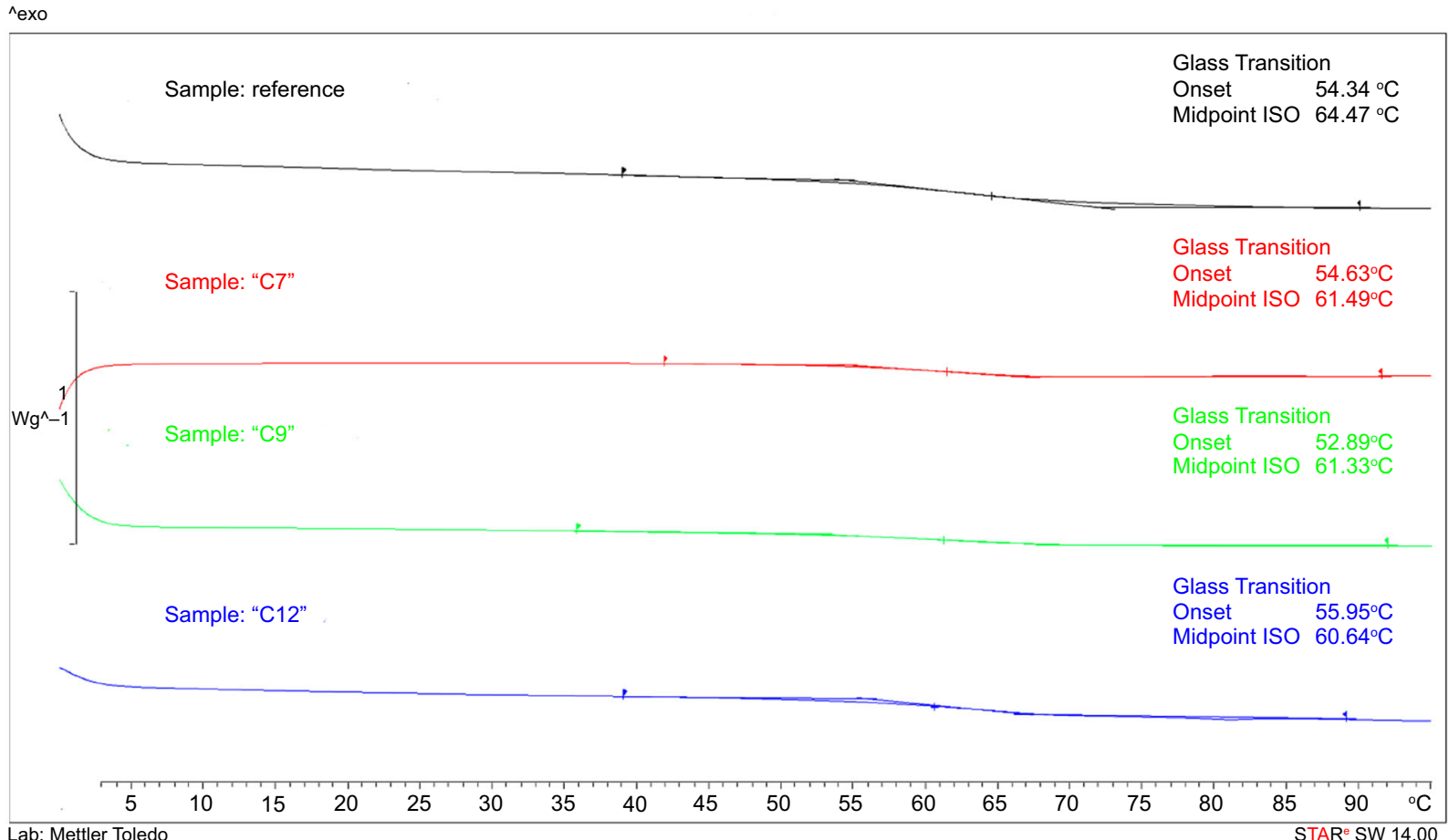

Fig. 9: DSC results of obtained epoxy coatings-second heating cycle 
the rising amount of -CF groups. The fluorine content should be then carefully considered to avoid excessive glass transition changes, especially in the case of materials working in low temperatures.

Acknowledgments This work was supported by the National Centre for Research and Development under the 9th edition of the LIDER programme through the Project contract No. LIDER/47/0194/L-9/17/NCBR/ 2018 "Technology development for the production of passive antiicing systems based on innovative superhydrophobic epoxy nanocomposite coatings."

Open Access This article is licensed under a Creative Commons Attribution 4.0 International License, which permits use, sharing, adaptation, distribution and reproduction in any medium or format, as long as you give appropriate credit to the original author(s) and the source, provide a link to the Creative Commons licence, and indicate if changes were made. The images or other third party material in this article are included in the article's Creative Commons licence, unless indicated otherwise in a credit line to the material. If material is not included in the article's Creative Commons licence and your intended use is not permitted by statutory regulation or exceeds the permitted use, you will need to obtain permission directly from the copyright holder. To view a copy of this licence, visit http://creativecommons.org/licenses/by/4.0/.

\section{References}

1. Ghaffari, S, Aliofkhazraei, M, Barati Darband, G, Zakeri, A, Ahmadi, E, "Review of Superoleophobic Surfaces: Evaluation, Fabrication Methods, and Industrial Applications." Surf. Interfaces, 17100340 (2019)

2. Qin, C, Mulroney, A, Gupta, M, “Anti-icing Epoxy Resin Surface Modified by Spray Coating of PTFE Teflon Particles for Wind Turbine Blades." Mater. Today Commun., 22 100770 (2020)

3. River, PJ, Rodriguez, RJ, Larumbe, S, Monteserin, M, Martin, F, Garcia, A, Acosta, C, Clemente, MJ, García, P, Mora, J, Agüero, A, "Evaluation of Functionalized Coatings for the Prevention of Ice Accretion by Using Icing Wind Tunnel Tests." Coatings, 10636 (2020)

4. Sun, Y, Sui, X, Wang, Y, Liang, W, Wang, F, "Passive AntiIcing and Active Electrothermal Deicing System Based on an Ultraflexible Carbon Nanowire (CNW)/PDMS Biomimetic Nanocomposite with a Superhydrophobic Microcolumn Surface." Langmuir, 36 14483-14494 (2020)

5. Wang, T, Zheng, Y, Abdul-Rahman, OR, Li, Y, Sikkema, WKA, Tour, JM, "Passive Anti-Icing and Active Deicing Films." ACS Appl. Mater. Interfaces, 8 (22) 14169-14173 (2016)

6. Jin, FL, Li, X, Park, SJ, "Synthesis and Application of Epoxy Resins: A Review." J. Ind. Eng. Chem., 29 1-11 (2015)

7. Wu, X, Zheng, S, Bellido-Aguilar, D, Silberschmidt, V, Chen, Z, "Transparent Icephobic Coatings Using Bio-based Epoxy Resin.” Mater. Des., 140 516-523 (2018)
8. Zheng, S, Bellido-Aguilar, D, Wu, X, Zhan, X, Huang, Y, Zeng, X, Zhang, Q, Chen, Z, "Durable Waterborne Hydrophobic Bio-epoxy Coating with Improved Anti-icing and Self-cleaning Performance." ACS Sustain. Chem. Eng., 7 641-649 (2019)

9. Zhang, F, Qian, H, Wang, L, Wang, Z, Du, C, Li, X, Zhang, D, "Superhydrophobic Carbon Nanotubes/Epoxy Nanocomposite Coating by Facile One-step Spraying." Surf. Coat. Technol., 341 15-23 (2018)

10. Lu, J, Zhu, C, Qiu, H, Zhang, J, Gu, C, Feng, J, "Robust Icephobic Epoxy Coating Using Maleic Anhydride as a Crosslinking Agent." Prog. Org. Coat., 142105561 (2020)

11. Bellido-Aguilar, D, Zheng, S, Huang, Y, Zeng, X, Zhang, Q, Chen, Z, "Solvent-Free Synthesis and Hydrophobization of Biobased Epoxy Coatings for Anti-Icing and Anticorrosion Applications." ACS Sustain. Chem. Eng., 7 19131-19141 (2019)

12. Qin, C, Mulroney, A, Gupta, M, “Anti-Icing Epoxy Resin Surface Modified by Spray Coating of PTFE Teflon Particles for Wind Turbine Blades." Mater. Today Commun., 22 100770 (2020)

13. Van De Grampel, RD, Ming, W, Van Gennip, WJH, Van Der Velden, F, Laven, J, Niemantsverdriet, JW, Van Der Linde, R, "Thermally Cured Low Surface-Tension Epoxy Films." Polymer, 46 10531-10537 (2005)

14. Minisini, B, Rolère, S, Coulon, JF, Poncin-Epaillard, F, "Influence of the Chemical Composition and Formulation of Fluorinated Epoxy Resin on Its Surface Characteristics." Eur. Polym. J., 112 452-460 (2019)

15. Milchert, E, Smagowicz, A, Lewandowski, G, "Epoksydowanie oleju rzepakowego nadkwasami." Org. Process Res. Dev., 14 1094-1101 (2010)

16. Glaris, P, Coulon, JF, Dorget, M, Poncin-Epaillard, F, "Fluorinated Epoxy Resin as a Low Adhesive Mould for Composite Material." Compos. Part B: Eng., 63 94-100 (2014)

17. Miccio, LA, Fasce, DP, Schreiner, WH, Montemartini, PE, Oyanguren, PA, "Influence of Fluorinated Acids Bonding on Surfaces Properties of Crosslinked Epoxy-Based Polymers." Eur. Polym. J., 46 744-753 (2010)

18. Piłkowski, M, Morgiante, G, Myśliwiec, J, Kuchowicz, M, Marczak, J, "Environmental Testing of Hydrophobic Fluorosilane-Modified Substrates." Surf. Interfaces, 23100987 (2021)

19. Marczak, J, Kargol, M, Psarski, M, Celichowski, G, "Modification of Epoxy Resin, Silicon and Glass Surfaces with Alkyl- or Fluoroalkylsilanes for Hydrophobic Properties." Appl. Surf. Sci., 380 91-100 (2016)

20. Fox, HW, Zisman, WA, "The Spreading of Liquids on LowEnergy Surfaces. II. Modified Tetrafluoroethylene Polymers." J. Colloid Sci., 7 109-121 (1952)

21. Schulman, F, Zisman, WA, "The Spreading of Liquids on Low-Energy Surfaces. V. Perfluorodecanoic Acid Monolayers." J. Colloid Sci., 7 465-481 (1952)

22. Matuszczak, S, Feast, WJ, "An Approach to Fluorinated Surface Coatings via Photoinitiated Cationic Cross-Linking of Mixed Epoxy and Fluoroepoxy Systems." J. Fluorine Chem., 102 269-277 (2000)

23. Psarski, M, Celichowski, G, Bystrzycka, E, Pawlak, D, Grobelny, J, Cichomski, M, "Vapor Phase Deposition of Fluoroalkyl Trichlorosilanes on Silicon and Glass: Influence of Deposition Conditions and Chain Length on Wettability and Adhesion Forces." Mater. Chem. Phys., 204 305-314 (2018) 
24. Ronneberg, S, He, J, Zhang, Z, "The Need for Standards in Low Ice Adhesion Surface Research: A Critical Review." $J$. Adhes. Sci. Technol., 34 319-347 (2020)

25. Hejazi, V, Sobolev, K, Nosonovsky, M, "From Superhydrophobicity to Icephobicity: Forces and Interaction Analysis." Sci. Rep., 3 1-6 (2013)

26. Mirishandi, K, Zarasvand, KA, Luo, W, Golovin, K, "A High Throughput Tensile Ice Adhesion Measurement System." Hardware X, 800146 (2020)

27. Tudorachi, N, Mustata, F, "Curing and Thermal Degradation of Diglycidyl Ether of Bisphenol A Epoxy Resin Crosslinked with Natural Hydroxy Acids as Environmentally Friendly Hardeners." Arab. J. Chem., 13 (1) 671-682 (2020)

28. Onur Yılmaz, O, Kılıçarislan Özkan, Ç, Yılmaz, CN, Yorgancioğlu, A, Özgünay, H, Karavana, HA, "Synthesis and Characterization of Functional Acrylic Copolymers via RAFT Mini-emulsion Polymerization.” AIP Conf. Proc., 1918020006 (2017)

29. Abdollahi, H, Salimi, A, Barikani, M, Samadi, A, HosseiniRad, S, Zanjanijam, AR, "Systematic Investigation of
Mechanical Properties and Fracture Toughness of Epoxy Networks: Role of the Polyetheramine Structural Parameters.” J. Appl. Polym. Sci., 136 (9) 47121 (2018)

30. Bulusheva, L, Fedoseeva, Y, Flahaut, E, Rio, J, Ewels, C, Koroteev, V, Van Lier, G, Vyalik, D, Okotrub, A, "Effect of the Fluorination Technique on the Surface-Fluorination Patterning of Double-Walled Carbon Nanotubes." Beilstein J. Nanotechnol., 8 1688-1698 (2017)

31. Kyriakou Tziamtzi, C, Chrissafis, K, "Optimization of a Commercial Epoxy Curing Cycle via DSC Data Kinetics Modelling and TTT Plot Construction." Polymer, 230124091 (2021)

Publisher's Note Springer Nature remains neutral with regard to jurisdictional claims in published maps and institutional affiliations. 